\title{
A Load-Interactive Model for Predicting the Performance of Autogenous and Semi-Autogenous Mills
}

\author{
Homero Delboni J $r$. \\ Dept. of M ining and Petroleum Engineering \\ University of São Paulo* \\ Steve Morrell \\ Julius Kruttschnitt M ineral Research Centre \\ University of Queensland **
}

\begin{abstract}
The Julius Kruttschnitt Mineral Research Centre (JKMRC) has been involved in the study and modelling of industrial autogenous ( $A G)$ and semi-autogenous (SAG) mills for over 25 years. Recent research at the JKMRC has developed a new AG/SAG mill model which is based on charge dynamics. The model relates charge motion and composition to power draw and size reduction. Size reduction is described by considering impact and attrition/abrasion as separate processes. These are linked to energy available in the mill, the charge size distribution and the relative motion of the grinding media. Ore specific energy-breakage are described using laboratory data which are obtained from breakage tests over a wide range of energies and particle sizes. Slurry transport is described using the JKMRC's latest model which incorporates the effect of grate design. This paper describes the overall structure of the model together with its main sub-processes.
\end{abstract}

\section{Introduction}

The word autogenous is derived from the Greek autogenes which means self (auto) generated, born or produced (genes). In mineral processing however, autogenous grinding designates generically the action of rocks grinding upon themselves, as occurring in tumbling mills. For reasons that will be further addressed in this work, grinding in autogenous (AG) mills is frequently assisted by steel balls, in which case it is called semi-autogenous (SAG) grinding.

Conceptually, any AG/SAG mill consists of a rotary cylindrical metallic chamber in which the feed is continuously introduced through the hollow feed trunnion at one end and discharged to another. The discharge mode does vary substantially between hollow discharge trunnions to screen plates (grates) that can be either placed at the periphery of the cylinder or radially to the trunnion. The mill shell is internally protected by means of steel liners.

Today's extensive use of AG/SAG mills is credited to the combination of relative high throughput and

\footnotetext{
* Av. Prof. M ello M oraes, 2373 - São Paulo, SP 05508-900 Brazil

** Isles Rd. Indooroopilly QLD 4075 Australia

† Accepted: October 28, 2002
}

high reduction ratios allied with compactness of their physical installations. There is, consequently, an increasing demand for techniques, which enable the prediction of the performance of such equipment, under a wide range of conditions. $M$ athematical modelling and simulation have proven to be a reliable technique to assist the development of comminution circuits in conceptual design, scale-up from pilot plant test work and the optimisation of industrial operations. Over the last 30 years J KM RC has been continuously developing mathematical models of AG/SAG mill performance. The current model is incorporated in a computer program for process simulation JKSimM et, which has been used successfully to simulate a number of closed and open circuit situations. It is arguably the most popular and widely used model in the world. There are, however, a number of areas where the model is still limited in its ability to predict the effect of changes in operational variables. In particular its limited inherent ability to relate the performance with charge composition and motion is seen as a major drawback. This has prompted the use of empirical "corrections" to the model (M utambo, 1992; Morrell and Morrison, 1996), which resulted in the formulation of equations that have been only partially successful. Significant progress has been recently achieved towards the modelling of mill charge 
donamies, particularly those related to the effect of lifter bar design and the estimation of mill power wdraw. These progresses have been based on physically sound descriptions of the charge motion and the principal variables, which affect it. This scenario of increasing demand for a comprehensive model and the development of better knowledge of charge dynamics, lead to the initiation of a new AG/ SAG mill mathematical model.

\section{Objective}

The main objective of this work is to describe the influence of the charge composition and motion on breakage performance such that it can predict the performance of the mill under all normally encountered operational conditions. The derived model should then incorporate a number of operating conditions as they influence the charge dynamics and therefore the breakage mechanisms involved in AG/SAG grinding as opposed to a rate process approach.

\section{Review of AG/SAG Grinding Process Models}

Researchers involved with power prediction were motivated by the possibility of reducing the large amounts of energy consumed in comminution plants. Accordingly, the energy-size relationships, or "laws of comminution" were extensively used in attempts to predict the power draw by crushers and ball/ rod mills, based on one characteristic of the broken material. However, the energy approach proved to be inadequate for meaningful process simulation, specially in AG/SAG mills where the mill charge weight varied substantially.

The difficulty in maintaining the operation of $A G$ mills in steady state motivated research groups to develop models to predict and control their dynamic behaviour. Such models were based on statistical correlations thus representing an intermediate stage towards more comprehensive approaches (Kelly, 1970). Three lines of models were since then pursued to model AG/SAG mills i.e., matrix models, kinetic models and perfect mixing models. However, following the evolution of computers, kinetic and perfect mixing models received much more attention from research programmes, to the detriment of matrix models, which were eventually abandoned.

The majority of the models developed were essentially case-specific and strongly dependent on site conditions. M oreover, they were not designed to take into account the mechanisms involved in the process.

Wickham (1972) first incorporated the per fect mixing equation (Whiten, 1974) to AG/ SAG modelling. A simplified matrix form was used, in which a condensed term adapted the model structure to ignore both load and discharge rate. Two distinct functions for rock breakage were considered i.e. impact and abrasion, but were non-ore specific.

Stanley (1974) published the first successful effort to model AG/SAG mills according to a mechanistic approach, as a result of a series of survey campaigns on both pilot plant and industrial mills. The underlying mechanism assumed was that AG/SAG mills are mixers in which both transport and breakage occurs. Fur thermore, when rock fragments collide inside the mill, they generate broken particles, which will be distributed in other size fractions. Although the concepts used by Stanley were essentially mechanistic, the model created can be better classified as a phenomenological, because the mechanisms involved were treated as rate processes rather than genuine physical interactions, which could be predicted from simple generic laws.

Austin et al (1977) developed an AG/SAG model structure based on the kinetic model. The mean residence time of the particles within the load was used to correlate the batch grinding conducted in the laboratory, to the performance of pilot plant and industrial mills.

Leung (1987) used the perfect mixing model equation in its full form as well as a mass transfer empirical relationship. Leung developed a combined ore-dependent impact and abrasion function for describing breakage. Although average values were established, breakage rates were mill/ ore dependent thus had to be fitted.

M orrell and Stephenson (1996) incorporated a phenomenological mass transfer relationship to Leung's model, based on an extensive work carried out on industrial mills.

\subsection{The Perfect Mixing Model}

The basic concepts of the perfect mixing model were developed by Whiten (1974) in which the rate of change of mill contents, due to breakage and flow, can be described by the following equation:

$$
p_{i}=d_{i} s_{i}=f_{i}+\sum_{j=1}^{i} a_{i j} r_{j} s_{j}-r_{i} s_{i}
$$

where

$f_{i}$ mass flow rate of size fraction $i$ in the mill feed

$p_{i}$ mass flow rate of size fraction $i$ in the mill discharge 
$s_{i}$ mass of size fraction $i$ in the mill load

de greakage rate of size fraction i

$a_{i j}$ appearance function (fraction of broken particles

from size fraction $\mathrm{j}$ which appears in size fraction $\mathrm{i})$

$d_{i}$ discharge rate of size fraction $i$

The perfect mixing model equation represents the mass balance of each individual size fraction of the mill charge. Accordingly, the entering particles (mill feed plus broken particles coming from coarser fractions of the charge) balance with the leaving particles (mill product plus the broken particles going to finer fractions of the charge).

\subsection{B reakage Mechanisms}

M uch work has been conducted on the determination of breakage mechanisms prevailing in tumbling mills. The results obtained in the analysis of rod and ball mill operation, which dominated the literature, are not adequate for AG/ SAG mill load analysis as the particle size range is more ample.

The majority of the authors dedicated to investigate the subject (Wickham, 1972; Stanley, 1974; Austin et al, 1977; M anlapig et al, 1979; Goldman et al, 1988, Kelly et al, 1990, Loveday et al, 1997) have selected a number of breakage mechanisms. Although a lot of controversy still persists in the literature, mainly derived from different nomenclatures for similar phenomena, the following mechanisms are considered to be predominant in AG/SAG mills: impact, abrasion, chipping and attrition.

It is important to emphasise that much of the confusion in the literature originates from the indistinct differentiation between cause and effect. The former is here defined as a combination of intensity and mode to impart energy to a fragment, while the latter is the resulted size distribution of broken fragments.

Schöenert (1993) affirmed that only the amount of energy imparted to a particle in any comminution machine should be considered to characterise the breakage event. The form of interaction is therefore irrelevant. However, both the breakage energy and mode are related to the motion of the charge. Hence, by relating the mode of breakage to charge dynamics, the energy associated with each mode can be determined.

A number of different tests to characterise the physical properties of material subjected to comminution are reported on the literature. They can be divided into those which are designed to reproduce the whole size reduction process within a mill (Bond, 1952; Kjos, 1985; M acPherson, 1987; M örsky et al,
1994), and the ones created to assess an individual fragmentation mechanism, specific of the AG/SAG mill process (Narayanan, 1985; King et al, 1993).

The characterisation tests relevant to the present work are those which correlate specific energy imparted to a rock fragment and its correspondent degree of breakage.

Based on the above discussions, this work considers three main modes to impart energy to any particle in AG/ SAG mills, which are showed schematically in Figure 1 and described below.

- Impact, here referred as the action of a falling charge element, including balls or rocks, onto the particles lying on the exposed part of the charge.

- Abrasion, which includes the rubbing action of rock particles against each other, against balls or mill liners.

- Attrition, including the mechanism of particles being nipped between steel balls and larger ore particles rolling and sliding against each other.

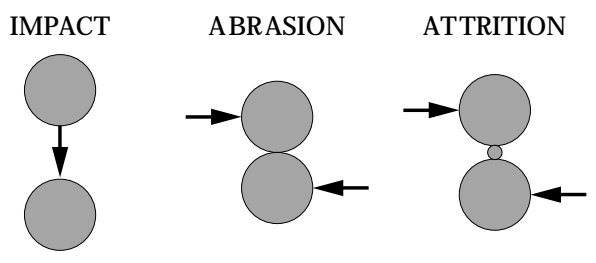

Fig. 1 Fragmentation M echanisms and the Resultant Size Distributions.

\subsection{B reakage Rates}

Breakage rates are associated with the frequency breakage events. Leung (1987) assumed that the breakage rates were fixed and calculated average values for AG and SAG mills separately. The breakage rate distribution was not described by back-calculated relationships, but in terms of five values, at $128,44.8$, 16.0, 4.0 and $0.25 \mathrm{~mm}$. The intermediate values for other sizes are calculated by interpolation which results in a smooth breakage rate curve as shown in

\section{Figure 2.}

The robustness of Leung's model contrasts with the fact that breakage rates are affected by a number of operating conditions instead of depending only upon the equipment. Morrell et al (1994) also showed that the influence of variables such as ball charge, ball size, feed size distribution determines the perfor- 


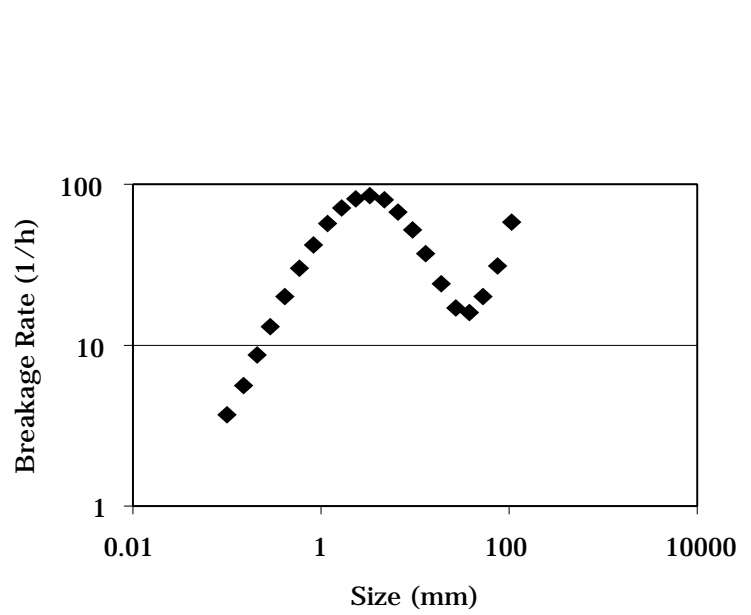

Fig. 2 B reakage Rate Distribution as Obtained by Leung.

mance of the process, thus directly affecting the breakage rate values.

As operating conditions determine breakage rates, difficulties were frequently experienced in predicting the performance of the mill under conditions much different from those used to fit the model parameters. In addition, design of full scale mills where no pilot data were available was limited to matching to the design of existing mills for which data were available.

The subject was investigated in detail by M utambo (1992) in an attempt to empirically cor relate breakage rate values with the operating conditions and design characteristics of a range of mills in the JKM RC database.

\section{The New Model}

\subsection{Description}

In grinding mills the kinetic energy that the rotation of the mill shell imparts to the grinding media is subsequently transferred to ore particles with which they are in contact, so causing breakage. The kinetic energy of these breakage events is related to both the size and velocity of the grinding media whilst the frequency of these events is associated with the number of grinding media and the rate at which they circulate within the mill. The process has a discrete nature, as it comprises many individual collisions or breakage 'events'. The product of these breakage events may leave the mill via the discharge grate due to entrainment by slurry, or remain within the charge to undergo further breakage.

It follows from these arguments that for modelling purposes it is necessary to have a description of at least the following:

- Energy associated with each breakage event and its relationship to the charge.
- Frequency of breakage events for each size fraction and its relationship to the charge.

- Size distribution of the products from each breakage event.

- Classification performance of the grate.

- Relationship between slurry hold-up in the mill and its flow rate out of the mill.

The assessment and modelling of each individual element listed above are summarised in the following sections.

The modelling approach adopted in this work is based on the interaction between mill charge motion and size reduction mechanisms, which is believed to resemble a real mill operation. Although the individual assessment of mill charge dynamics and size reduction mechanisms have progressed substantially, none of the published AG/SAG models are directly based on the interactions between them.

The charge is assumed to be comprised of two different fractions i.e. the one which causes breakage, described as grinding media or 'contactors', and the one which receive the contacts, or 'contactees'. The motion of the contactors will therefore determine both the frequency and the intensity of the size reduction mechanisms. The two mechanisms selected to represent the size reduction mechanisms in AG and SAG mills were impact and attrition, which therefore have to be described according to the approach adopted in the charge motion model.

Modelling of the charge motion was based on the approach adopted by M orrell (M orrell, 1993) for predicting the power draw of tumbling mills. The model assumes the mill charge to be comprised of concentric shells. The slip between the shells causes a shearing motion and creates the conditions necessary for attrition breakage where relatively small particles are nipped between grinding media as they slide against one another. Impact breakage occurs predominantly in the vicinity of the toe of the charge where the grinding media impact after falling from the shoulder of the charge.

The M orrell model differentiates between the power associated with each of these mechanisms individually and provides separate estimates of impact and attrition power.

The grinding media are viewed as "contactors" in the model and are used to determine the input energy for breakage in each of these modes. The model using the rate at which the charge rotates as well as the rate at which the shells slide against one another also provided an estimate of the total frequency of breakage events in each mode. 
Thorelationship between contactors and contactees is dessufmed to follow a pattern according to each mode of breakage. Underlying each of these relationships is the assertion that the surface area of the grinding media dictates the breakage frequency, whilst the probability that a contactee will be involved in a collision with a contactor is related to the surface area of the contactee.

The model operates in an interactive manner, which is believed to resemble a real mill operation. Therefore, after each iteration of the charge motion the grinding media is re-calculated according to the size reduction relationship. Accordingly, an arbitrary value of grinding charge volume is initially used as means to start the calculation of the charge size distribution. The grinding charge is considered to reach steady state after the constraint of fixed charge volume is eliminated and the grinding charge loop runs for a fixed number of iterations.

After each interaction the model calculates the slurry volume, which will fill the interstices of the grinding charge and may eventually raise above the grinding charge surface, thus giving rise to the formation of the slurry pool. If a slurry pool is formed, the next interaction will take into account its effect on the falling grinding media. The net result is a reduction of the impact velocity due to the buoyancy effect of the slurry pool.

The slurry volume is dictated by the discharge function and the mill throughput, together with the attrition mode of breakage, which is assumed to be prevalent on finer size fractions of the charge.

The mill charge motion is considered to be comprised of a number of shells, which slide against one another. Attrition breakage therefore occurs in the interstices between contiguous shells as well as in the voids of the grinding charge. It follows that for a breakage charge volume and mill charge motion there is a limited "volume associated to attrition sites" to be filled with particles. For situations where the charge slurry volume is smaller than the volume of attrition sites, no correction is necessary as any solid particle in the slurry will be within the breakage charge. However, as the slurry pool starts to build up in the mill chamber, the reverse occurs i.e. there will be more particles than breakage sites which decreases the attrition breakage performance of the mill. The model therefore incorporates a correction factor to take into account the slurry pool effect on attrition breakage.

After the stabilisation of the grinding charge loop, the model iterates until the entire charge size distrib- ution, charge volume and product size distribution stabilises.

One of the most prominent characteristics of the model resides on its structure and consequently on the mode in which it iterates. Instead of utilising the information to iterate backwards as most models do, the new model generates the necessary information based solely on the mill design characteristics, operating conditions and ore characterisation results, as input data. Therefore, the new model is not based on variables that are inherently operation dependent or necessitate scale-up procedures.

The fact that current AG/SAG mill models are not based on mill charge dynamics determines a number of limitations with them. Although a number of operating variables and mill design characteristics have been carefully assessed, they were incorporated in current models by simplistic parameterisation that limited their application.

The load-interactive approach adopted in the model incorporates a comprehensive description of the charge motion. Initially designed by M orrell (1993) to predict the power draw, the M orrell model was based on the location of the charge toe and shoulder for each shell, as the bulk of the charge was divided. The Morrell model was modified to incorporate Powell's (1991) equations for describing the trajectory of particles in contact with the lifter bars, including the effect of the angle of the lifter bar on the trajectory to be determined. Apart from the shell structure of the charge no assumptions are made about the shape that the charge takes up.

The net result is a model which predicts the motion of the grinding charge as well as the power draw under a wide range of operational and design conditions, and includes the effects of such factors as particle size, lifter bar geometry, mill filling and mill speed. The effects of the grate design is also directly included in the model as the discharge model is determined by grate open area and geometry. These factors are therefore incorporated into the size reduction part of the model.

The model also includes the prediction of the ball consumption of the simulated mill, together with the ball size distribution in the mill charge. The first is a characteristic not found in the current AG/SAG mill models even though it is valuable information in a mill design scenario. The estimation of the ball size distribution in the mill charge represents a significant decrease in the amount of input data to the model, which is also convenient for the user as this information is rarely available. 


\section{Model Structure}

whe model structure involves a number of sub processes according to different levels in a rather complex scheme. Figure 3 summarises the main structure of the model showing the input data, calculation loops and output data. Following the input of mill design characteristics, operating conditions and feed, the model begins execution by assigning an initial estimate of the mill charge volume.

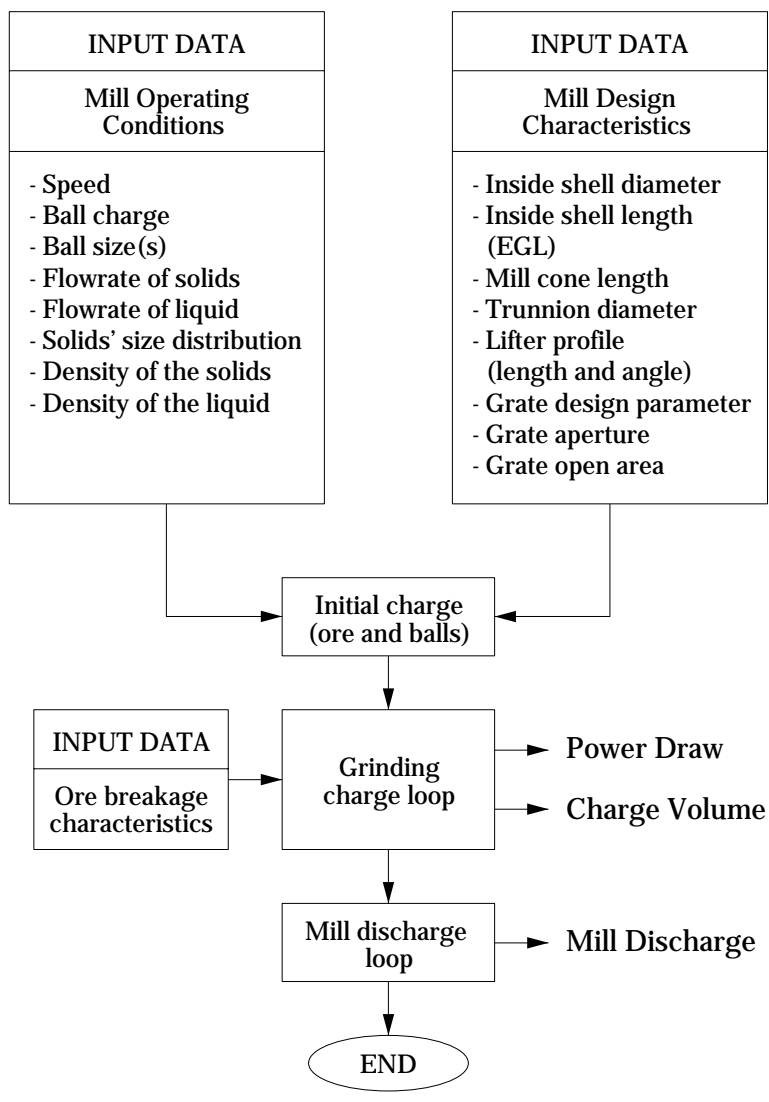

Fig. 3 Schematic Flow Sheet of the AG/ SAG M ill M odel.

The initial charge has the same size distribution as the mill feed, therefore resembling the start of the mill operation. The initial charge enters the grinding charge loop following an iterative process that provides the charge volume and mill power draw based on the mill charge motion and ore breakage characteristics. As the grinding charge loop reaches the stabilisation criterion, the model proceeds to the calculation of the mill discharge size distribution and thus finishing the cycle. Both grinding charge loop and mill discharge loop are further discussed in the following sections.

\subsection{Grinding Charge Loop}

Figure 4 shows in detail the schematic flow sheet of the grinding charge loop. Initially, the charge motion model provides the first estimation of the initial charge breakage energy and frequency based on the calculated characteristic media size. The total breakage energy and frequency are divided according to each of the breakage mechanism i.e. impact and attrition. The energy is then distributed to each size fraction which results in the estimation of individual values of impact and attrition specific breakage energies for all particle sizes.

The breakage of each size fraction according to both impact and attrition are calculated considering the individual values of breakage energy together with the ore breakage characteristics.

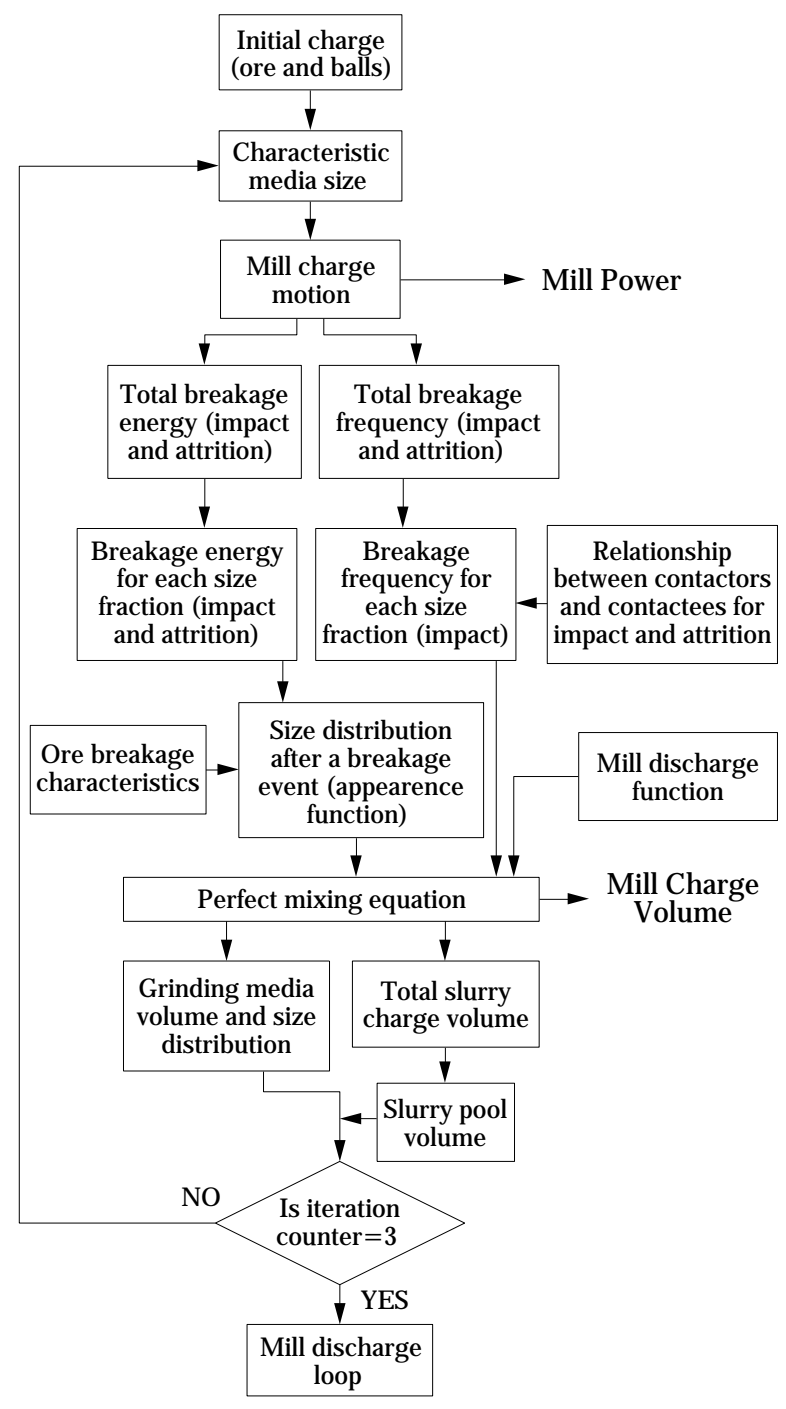

Fig. 4 Grinding Charge Loop. 
Thorirequency of contacts follow the same procedure as the total amount of contacts is distributed to each size fraction according to a relationship between contactors and contactees. The resulting breakage of each individual size fraction is then calculated on the basis of breakage energy and frequency.

A discharge rate is associated with each size fraction using a hold-up - flow rate model. M athematically the various sub processes are brought together according with a extended version of the perfect mixing model equation, as follows:

$$
\mathrm{f}_{i}-\mathrm{d}_{i} s_{i}+\sum_{j}^{i-1} s_{j}\left(a_{i j}^{i m p} r_{j}^{i m p}+a_{i j}^{a t t} r_{j}^{a t t}\right)-s_{i}\left[r_{i}^{i m p}\left(1-a_{i i}^{i m p}\right)+r_{i}^{a t t}\left(1-a_{i i}^{a t t}\right)\right]=0
$$

where

$r_{i}{ }_{i m p}$ impact breakage rate of size fraction $i$

$r_{i}{ }^{\text {att }}$ attrition breakage rate of size fraction $i$

$a_{i j}$ imp impact appearance function

$\mathrm{a}_{\mathrm{ij}}{ }^{\text {att }}$ attrition appearance function

Therefore, after each interaction the model estimates the total volume, which is discharged out of the mill through the grate. The discharge rate is calculated using a hold-up flow rate model (Morrell and Stephenson, 1996) in combination with the classification function, resulting in the following equation:

$$
d_{i}=C_{i} Q^{0.5} A^{0.5} \gamma^{1.25} \phi^{-0.67} D^{0.25} V_{m}^{-1}
$$

where

$C_{i}$ classification function at size I

Q flowrate through the grate

A grate open area

$\gamma$ mean relative position of the grate apertures

$\phi$ fraction of mill critical speed

D mill diameter

$V_{m}$ volume of the mill charge

The net result after the discharged volume calculation is a new grinding charge volume and new grinding charge size distribution, which serves as the starting values for subsequent interactions. At this stage the model estimates the total slurry volume in the mill charge comprising the finer fractions of ore together with the water held-up in the mill.

As the model assumes that only part of the charge will determine the frequency and intensity of the breakage events, the structure was configured in a way to first establish a stable grinding charge. Therefore, after each iteration of the charge motion the grinding media is re-calculated according to the size reduction relationship. The grinding charge is considered to reach steady state after the constraint of fixed charge volume is eliminated and the grinding charge loop runs for a fixed number of iterations.

After each interaction the model calculates the slurry volume, which will fill the interstices of the grinding charge and may eventually raise above the grinding charge surface, thus giving rise to the formation of the slurry pool. If a slurry pool is formed, the next interaction will take into account its effect on the falling grinding media. The net result is a reduction of the impact velocity due to the buoyancy effect of the slurry pool.

\subsection{Charge Motion}

The motion of the mill charge is caused primarily by the transfer of momentum from the mill shell to contiguous particles according to a succession of contacts. As there is a slip between particles, part of the imparted energy is dissipated, resulting in a loss of rotational rate among adjacent layers from the mill shell to the inner surface of the charge.

Morrell (1993) established an experimental campaign in a laboratory glass ended mill from which he was able to calculate a series of velocity profiles of mill charge according to variations in mill rotational speed, mill charge volume, particle size, among others. He derived a series of expressions, which allowed the charge angular velocity gradient to be calculated. $\mathrm{He}$ also derived expressions to calculate the position of toe and shoulder angles as a function of selected operating variables.

The subject is in fact one of paramount importance for mill operation, as it drives both the mill power draw and the comminution process performance. Accordingly, depending upon the amount of slip in the mill charge, the energy imparted to the charge will be split into attrition, abrasion or dissipated through heat as a by-product of friction.

However, it was assumed in the Morrell model that no slip occurs at the shell wall. Such a simplification is a valid first approximation in the case of AG/SAG mills, as it does not significantly influence the power draw by this equipment, which in fact was the main purpose of the Morrell model. Nevertheless, as a wide variety of lifter bar profiles are currently found in industrial units the comminution performance of the mill can be altered depending upon the specific application. M oreover, there is an increasing interest of industry towards a means of predicting the trajectory of the outer shells' particles as a function of the lifter bar profile. Most of that interest is motivated by the consequences of inadequately designed lifter bars, which have reportedly caused severe damage to mill shells ( Johnson et al, 1994). 
on is important therefore to separate the behaviour of shells whose trajectories are directly influenced by W the lifter bars and those which are not. The former are physically elevated by the action of the lifter bar surface thus showing no slippage with mill shell, whereas the latter are mostly influenced by the coefficient of friction between neighbouring shells.

Two distinct treatments were therefore adopted to predict both the shoulder and toe angles of individual shells. A theoretical one comprising the motion of those shells directly influenced by the lifter bars and an empirical one for the inner shells.

The theoretical approach was based on the work initiated by Vermeulen (1985) and further enhanced by Powell (1991), whilst the empirical one was based on Morrell (1993).

Once the trajectories of the shells influenced by the lifter bar are established, the remaining shell trajectories are determined based on Morrell's expressions to calculate the loss of rotational rate between contiguous shells, together with the empirical expressions for the shoulder and toe positions.

The net result of the above scheme was a model which predicts the motion of the grinding charge as well as the power draw under a wide range of operational and design conditions, and includes the effect of such factors as particle size, lifter bar geometry, mill filling and mill speed.

Apart from the shell structure of the charge no further assumptions were made about the shape that the charge takes up. However a lifelike prediction of the charge motion is provided by the model and is typified by the example shown below.

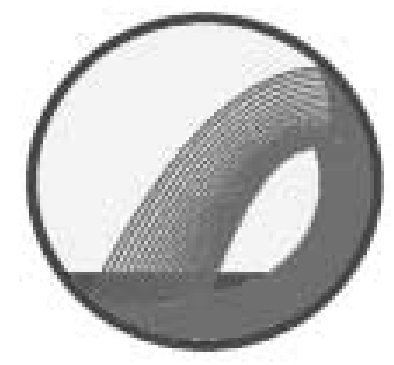

Fig. 5 Simulation of Charge M otion Profile.

\subsection{Breakage Energy}

The new AG/SAG model differentiates the breakage processes occurring in AG/SAG mills into two main mechanisms. Accordingly, the slip between the shells causes a shearing motion and creates the conditions necessary for attrition breakage where rela- tively small particles are nipped between grinding media as they slide against one another. Impact breakage occurs predominantly in the vicinity of the toe of the charge where the grinding media impact after falling from the shoulder of the charge.

The Morrell model estimation of the bulk power associated with each of these mechanisms was the basis to establish the relationships, which associates the mill charge motion with specific comminution energy for all size fractions of the mill charge. The grinding media are viewed as contactors in the model and are used to determine the input energy for breakage in each of these modes.

The separation of impact from attrition was a departure from the way most models treat breakage. Until now it has been usual to describe breakage in terms of a single specific energy imparted to the particles, resulting from a combination from various size reduction mechanisms.

The motion of the charge was therefore described in terms of the breakage frequency and energy associated to each size reduction mechanism. Accordingly, the bulk power associated to the grinding charge according to impact and attrition was distributed to the entire charge of the mill. The interpretation of the physical mechanisms involved in the charge motion was therefore the basis to model the selected size reduction mechanisms independently.

To fully describe the model, it was necessary to have functions, which describe the way the total breakage frequency and energy is distributed amongst the size fractions of the contactees.

The total power associated with impact was directly derived from the mill charge motion model. The power attributed to impact was thus calculated from the power consumed by each shell to elevate the media elements and the frequency of contacts attributed to the media elements. The power consumed by individual shells was provided by the M orrell model.

The charge motion model adopted a shell description of the charge according to which all grinding media elements follow a circular trajectory up to the point where they enter a free fall trajectory. The cycle is completed as the grinding element re-enters the circular path at the toe of the charge.

To determine the rate at which breakage energy is imparted to the contactees, or the total number of impacts as shown in Figure 6, a simple approach was adopted by assuming that impact is directly related to the motion of the charge. These two assumptions were used to calculate the average energy associated with each impact event. From the shell description 


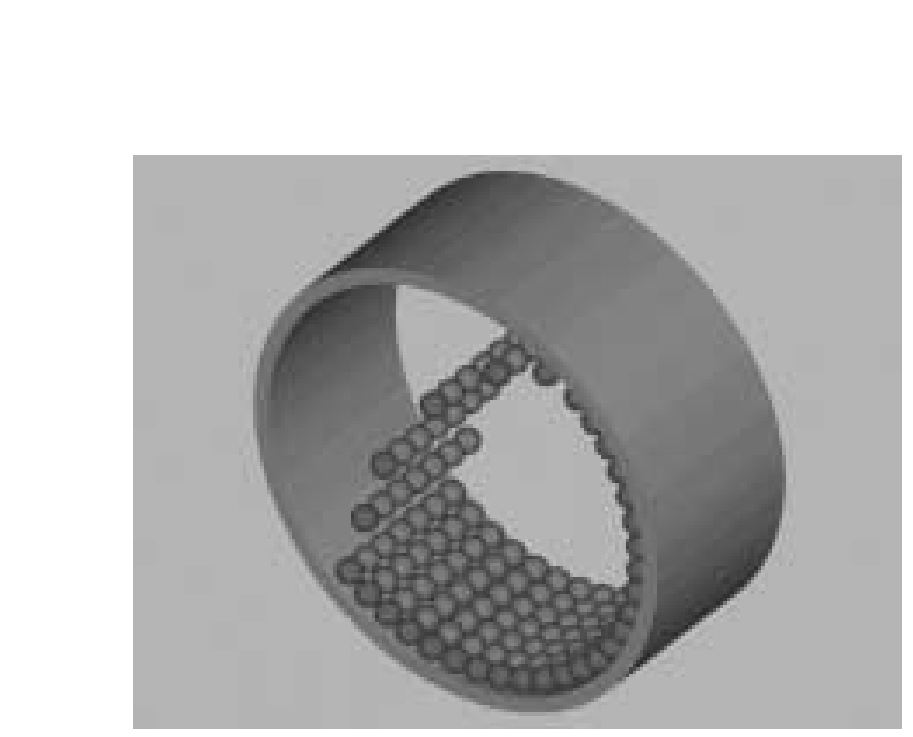

Fig. 6 Three-Dimensional Representation of a Shell Cycle.

used by the model the mean energy associated with each impact was then estimated.

Attrition breakage was considered to occur due to nipping in between media as they slide and roll over one another. It was fur ther assumed that attrition has an upper limit which is equal to the charge lower limit size i.e. attrition mode of breakage is restricted to particles smaller than those which form the grinding media.

The approach adopted to describe attrition energy was equivalent to the one described for impact. Accordingly, the energy attributed to attrition was calculated from the power consumed as a result of slip amongst contiguous shells and the frequency of contacts attributed to the media elements. The attrition power consumed by individual shells was provided by the M orrell model whereas the frequency of attrition events was determined from the relative velocity of contiguous shells and their surface area, as schematically described in Figures $\mathbf{7}$ and $\mathbf{8}$.

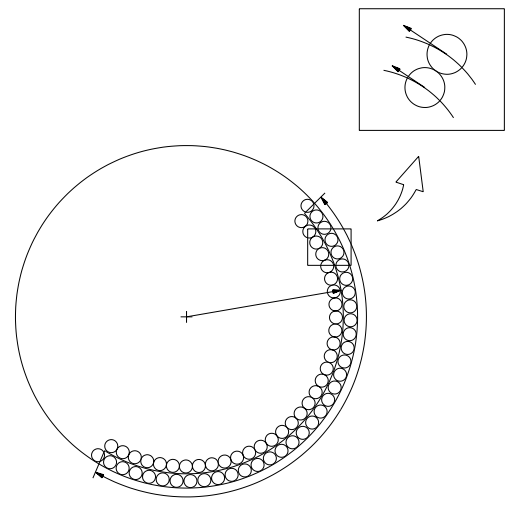

Fig. 7 Surface Formed Between Contiguous Shells with Different Rotational Speeds.

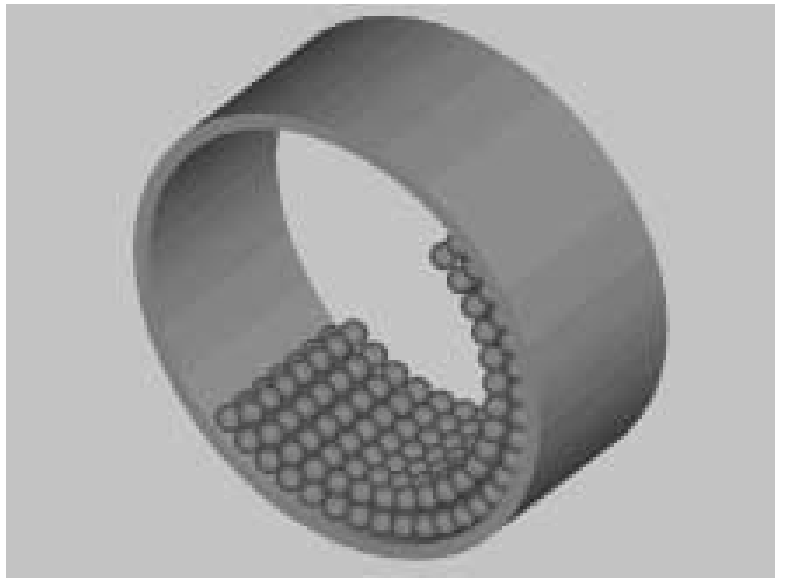

Fig. 8 Three-Dimensional Representation of the Surface Formed Between Contiguous Shells.

\subsection{B reakage Frequency}

The frequency at which impact and attrition breakage occur was considered to be the amount of impacts per particle per unit of time, according to the definition established by Morrell (1989). The definition of what constitutes a breakage event and its subsequent parameterisation was then necessary to describe the frequency at which the size reduction mechanisms occur in the mill.

The approach adopted in this work was based on the mechanistic description of the interactions between contactors and contactees. A more detailed interpretation was however necessary in order to establish a procedure to predict the breakage frequency associated with impact and attrition according to each mill charge size fraction.

The equations developed to represent both impact and attrition breakage frequency were based on the same approach i.e. the total number of breakage events associated with the contactors was distributed amongst the mill charge particles according to a partition term. These partition terms were established on the basis of the mechanisms derived from the charge motion and according to each specific size reduction mode used.

The impact events generated by the motion of the grinding media (impactors) are distributed amongst the impactees according to a mechanism based on surface area of the particles. Therefore, the estimation of impact breakage frequency involves two main terms i.e. a specific impact generation rate as well as a partition term, which divides such a rate of events amongst each individual size fraction. A secondary term was introduced as recourse to calibrate the relationship. 


\section{ip}

âf as rollows:

$r_{i}^{i m p}=\Gamma^{i m p} P_{i}^{i m p} K_{i}^{i m p}$

where

$r_{i}^{i m p}$ impact breakage frequency of size fraction $i$

$\Gamma^{i m p}$ specific impact generation rate

$P_{i}^{i m p}$ impact partition term

$\mathrm{K}_{i}{ }^{\mathrm{imp}}$ constant

The average number of impact contacts per particle comprises the ratio between the total number of impact contacts generated and the total number of particles which forms the grinding charge.

The total number of impact contacts was derived from the Morrell model, which was based on the grinding charge comprising solely of mono-sized particles. This number was subsequently normalised according to the number of grinding media particles. Numerically this relationship was expressed as follows:

$$
\Gamma^{\mathrm{imp}}=\left\{\frac{\sum_{1}^{n} \mathrm{~N}_{\mathrm{s}}^{\mathrm{imp}}}{\varepsilon}\right\}
$$

where

$\mathrm{N}_{s}^{\text {imp }}$ number of impact contacts per unit time given by shell s

$n$ number of shells

$\varepsilon \quad$ total number of grinding charge particles with an equivalent size equal to $C$, given by:

$$
\varepsilon=\left[\frac{\sum_{1}^{m}\left(s_{i}+s_{i}^{b}\right)}{\left[\frac{C^{3} \pi}{6}\right]}\right]
$$

where

$\mathrm{s}_{\mathrm{i}} \quad$ volume of all ore particles contained in size fraction i

$\mathrm{si}_{\mathrm{i}}^{\mathrm{b}} \quad$ volume of all steel balls contained in size fraction $\mathrm{i}$

$\mathrm{m}$ size fraction which contains media size lower limit value

C characteristic media size

The specific impact generation rate is the average frequency with which a grinding media element impacts the toe region.

The impact partition term represents the distribution of the impact breakage events provided by the grinding media elements to the impactees. Accordingly, this term incorporates the mechanism attributed to the interactions between impactors and impactees, according to which the surface area dictates the interactions.

The impacts generated by the entire ball charge were considered to act indistinctly on all impactees regardless of the particle size. It was assumed that below the toe of charge steel balls re-transmit any impact they received. This energy was therefore considered to be absorbed by the rock charge. Hence balls were not considered impactees.

As for impact, the attrition events generated by the motion of the grinding media (attritors) are distributed amongst the attritees according to a characteristic mechanism based on surface area of the particles. However, the effective attrition contacts i.e. those which cause attrition breakage, were considered to represent a size relationship between attritors and attritees. Accordingly, the model assumes that only a certain size of particle provides adequate sites to capture and subsequently break other particles by attrition.

\subsection{Ore Characterization}

The size distribution resulting from a breakage event, or appearance function, comprises the combination of the energy associated to the breakage event together with the results of the energy-breakage relationship calibrated for the ore investigated. Although two modes of imparting breakage energy to the particles were presented and further parameterised, the particle's response in terms of breakage is considered solely on the basis of the corresponding fragmentation, which results from the amount of energy imparted, regardless the mode of breakage. This is equivalent to assuming that even though the mode of applying energy to a particle in a AG/SAG mill may vary substantially, the resulting breakage will depend only on the particle characteristics and the total amount of energy received by the particle.

The ore breakage characterisation data resulted from two particular laboratory tests, which were developed at JKMRC i.e. the drop-weight impactor and the tumbling test ( Napier-M unn et al, 1996).

The drop-weight impactor is able to accommodate particles in the size range $10-100 \mathrm{~mm}$ thus covering the range of sizes typically found in the grinding media of AG and SAG mills. It is used to generate energy-breakage data comprising usually a 0.25 to 2.5 $\mathrm{kWh} /$ tonne range of specific energies applied to particles. The test reproduces breakage events carried out on individual particles, even though in a typical programme a number of particles are tested as to minimise the effects of ore heterogeneity as well as 
experameratal errors. Figure 9 shows a schematic of the J J Kir RC drop weight testing device.

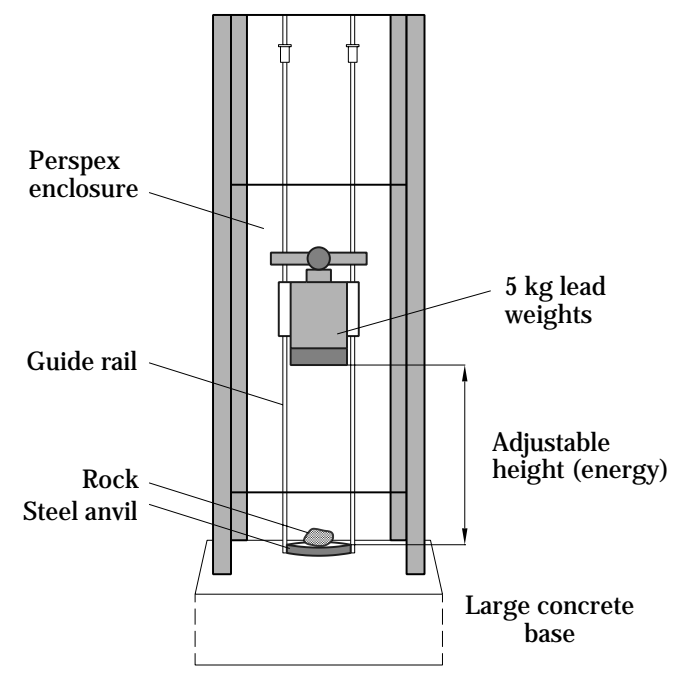

Fig. 9 The JKM RC Drop-Weight Testing Device.

The autogenous tumbling test was designed to create an environment where the breakage energy imparted to each particle is very small thus resulting in size reduction typical of abrasion and chipping. The data generated from this test were re-interpreted not as a secondary parameter to the model but instead, in terms of a energy-breakage relationship.

The experimental data obtained from drop-weight and tumbling tests were treated separately according to the procedures described in previous sections. The information derived from such treatment were combined into a single system which constitutes the ore breakage characterisation, fur ther used by the model to calculate the appearance function.

The breakage characterisation system adopted by the AG/SAG model consists of two complementary groups of information. The first group involves the relationship between specific energy associated to a breakage event and a breakage parameter representing a single point of the size distribution of corresponding broken particles. Accordingly, the specific energy ( $\mathrm{kWh} /$ tonne) values derived from the dropweight test impacts were associated with a breakage parameter obtained from the sizing of broken fragments, in this case $t_{10}$ or the percent passing at onetenth of the original fragment size. The specific energy $\left(E_{c s}\right)$ and breakage parameter $\left(t_{10}\right)$ relationship was described in terms of a matrix, as shown in the first two columns of Table $\mathbf{1}$. The information obtained from the tumbling test was directly incorporated to this matrix as noted in the first line. The combination of results from both drop-weight device and tumbling tests provided a comprehensive assessment to the energy/ breakage relationship.

The second group of information related the breakage parameter $t_{10}$ to the entire size distribution of broken fragments. The $t_{10}$ was therefore associated with $t_{2}, t_{4}, t_{100}$ or the other $t_{n}$ 's which characterise the corresponding size distribution. The full size distribution is predicted by successive interpolations conducted over the regressed $t_{n}$ values. The tumbling test results were also included into the drop-weight $t_{10} / t_{n}$ matrix as an extra line, as shown in Table $\mathbf{1 .}$

Table 1 Relationship Between $E_{c s}$ and $t_{n}$.

\begin{tabular}{|c|c|c|c|}
\hline \multirow{2}{*}{$\begin{array}{c}E_{c s} \\
\text { (kWh/ tonne) }\end{array}$} & \multirow{2}{*}{$\begin{array}{c}\mathrm{t}_{10} \\
(\%)\end{array}$} & \multicolumn{2}{|c|}{ Parameter $\mathrm{t}(\%)$} \\
\cline { 2 - 4 } & $\mathrm{t}_{2}$ & $\mathrm{t}_{100}$ \\
\hline $6.0 \times 10^{-4}$ & $1.77 \times 10^{-2}$ & $1.87 \times 10^{-2}$ & $1.38 \times 10^{-2}$ \\
0.50 & 20 & 63.1 & 7.5 \\
1.25 & 30 & 84.2 & 11.4 \\
2.50 & 50 & 99.9 & 20.2 \\
\hline
\end{tabular}

\section{Validation}

The model validation exercise represents a critical step in the analysis of the model's ability to reproduce a real mill operation and, by extension, establishes the limits of the model's application as well. Accordingly, the new AG/SAG mill model was evaluated on its predictive capacity to resemble the interactions between the load and mill operating conditions. The simulations thus aimed to assess the load composition as influenced by different conditions on the resulting breakage and power draw. The analysis included the load interaction with the following variables:

- Mill Throughput

- Slurry Pooling

- Grate Design and Open Area

- Lifter Bar Design

- Mill Speed

- Ore B reakage Characteristics

Industrial AG/SAG mills have a characteristic relationship between the load and the mill throughput, which tends to be more prominent as the ball charge decreases. Accordingly, the load of an industrial AG mill increases with throughput up to a point where the increments will decrease progressively. This is equivalent to say that there is a non-linear relationship 
ditions and design characteristics not included in existing models, its predictive capacity was compared with Leung's AG/ SAG model. The comparisons were conducted in terms of the most significant variables of the mill performance i.e. power draw and discharge size distribution.

Each of the models was then applied to an industrial mill database and the relative error of their predictions calculated. The comparisons were based on the predictions relative to the mill power draw and mill discharge $P_{80}$. Table 2 summarises the individual values obtained according to each data set and model used. The mean relative er ror and standard deviation were calculated for each set of model predictions.

The fact that the new AG/SAG model predicted steady mill charges for all the 17 data sets as opposed to the other model tested indicated its superior capacity to reproduce the database. However, as Leung imposed no limits for the mill charge, it was decided to conduct the comparisons using the charge volumes as predicted by the models.

The results showed in Table $\mathbf{2}$ indicated generally very high values of the standard deviation associated with the mean relative error. Accordingly, although the mill power draw predictions showed relatively

Table 2 Predictions of M ill Power Draw and Product Size Distribution.

Fig. 10 Relationship Between M ill Load and Throughput.

It is clear from Figure $\mathbf{1 0}$ that the simulations using Leung's model resulted in tendency of a linear relationship between the mill throughput and mill load whereas the new model showed a non-linear response. Accordingly, both Leung's and new model load level predictions coincides at the throughput of 250 tonne/ $\mathrm{h}$ which in this case was equivalent to $19 \%$ of mill volume. However, from this point onwards Leung's model predicts mill loads up to more than $55 \%$ as the through put increases whilst the new model shows a tendency to flat out at $40 \%$ of the mill volume.

Even tough the survey campaign carried out on the selected mill operation did not include a step change procedure to validate the above simulated results, the new model clearly resembles the industrial mill operation as opposed to the results obtained with Leung's model.

Although the new AG/SAG mill model was designed to incorporate a number of mill operating con-

\begin{tabular}{|c|c|c|c|c|c|c|}
\hline \multirow{2}{*}{$\begin{array}{c}\text { Opera- } \\
\text { tion/ } \\
\text { Survey }\end{array}$} & \multicolumn{3}{|c|}{$\begin{array}{c}\text { M ill Power Draw } \\
\text { (M W) }\end{array}$} & \multicolumn{3}{c|}{$\begin{array}{c}\text { M ill Discharge P80 } \\
\text { (mm) }\end{array}$} \\
\cline { 2 - 7 } M ill \#1 & Exper. & Leung & N ew & Exper. & Leung & New \\
1 & 7.13 & 7.77 & 7.12 & 0.97 & 2.22 & 1.42 \\
2 & 6.85 & 7.53 & 7.04 & 1.13 & 4.97 & 1.31 \\
3 & 7.13 & 7.43 & 7.04 & 0.96 & 8.19 & 1.90 \\
4 & 6.77 & 7.33 & 6.55 & 1.13 & 5.72 & 1.75 \\
\hline Mill \#2 & & & & & & \\
1 & 5.76 & 3.85 & 3.91 & 0.24 & 0.27 & 0.42 \\
2 & 2.34 & 3.72 & 2.60 & 0.82 & 0.34 & 0.32 \\
3 & 3.28 & 5.15 & 4.60 & 1.02 & 0.33 & 0.55 \\
4 & 3.93 & 5.76 & 4.89 & 0.86 & 0.32 & 1.50 \\
5 & 6.07 & 5.02 & 5.79 & 0.69 & 0.34 & 0.60 \\
6 & 5.72 & 4.55 & 4.80 & 0.58 & 0.28 & 0.50 \\
7 & 6.07 & 6.24 & 4.82 & 1.08 & 0.33 & 0.47 \\
8 & 5.68 & 4.40 & 4.98 & 0.26 & 0.28 & 0.28 \\
9 & 5.95 & 5.41 & 4.37 & 1.43 & 0.32 & 1.73 \\
\hline Mill \#3 & & & & & & \\
1 & 2.50 & 2.88 & 2.80 & 0.44 & 0.62 & 0.44 \\
2 & 2.60 & 2.00 & 1.95 & 0.20 & 0.45 & 0.42 \\
3 & 2.45 & 2.30 & 2.24 & 0.40 & 0.50 & 0.33 \\
4 & 2.63 & 2.89 & 2.85 & 0.89 & 0.67 & 0.43 \\
\hline Relative & Mean & -7.1 & 1.7 & & -78.2 & -8.4 \\
\cline { 2 - 7 } Error & Std. Dev. & 27.3 & 18.6 & & 230.6 & 50.3 \\
\hline
\end{tabular}


loweramean values the standard deviations varied in the range of 18.6 to $27.3 \%$ The new AG/ SAG model is better than Leung's as determined by the respective relative error means and standard deviations. Accordingly, the new model over predicted the power draw by $1.7 \%$ whilst the other model under predicted by $7.1 \%$

The predicted mill discharge size distributions represented by the $P_{80}$ parameter showed a totally different picture as the new model resulted much superior than the other model. The new model provided the lowest standard deviation of the relative error (50.3\%) whereas the other model resulted in a corresponding value of $231 \%$

Overall the new model provided the lowest mean relative error and standard deviation for both mill power draw and mill discharge size distributions.

\section{Additional Model Features}

The slurry accumulation within the mill load was investigated in terms of its effects on mill performance for all 17 data sets. A series of comparisons between different circuit configurations showed that the effects caused by slurry pooling at both impact and attrition terms of the new model resulted in correct tendencies of both mill power draw and mill discharge size distribution.

The simulations designed to assess the mill performance caused by grate design and total open area predicted variations of slurry hold up in the mill charge according to the expected behaviour of a full scale mill. The results should therefore be coupled with effects of slurry pooling on the mill power draw and discharge size distribution.

The new model incorporated the effects of the lifter bar design on the mill performance. The simulated mill performance reflected accordingly the changes in the charge motion. Supplementary information was obtained as the simulations indicated whether the points of impact associated with the outer shells were onto the charge or the mill liner. This is a potential feature for optimisation of the lifter bar profile. Figure 11 shows the representation of a simulated charge profile.

The effects of mill speed on the charge motion were evaluated. The results indicated consistent variations of charge volume and corresponding mill power draw. The mill discharge size distribution reflected accordingly the relative variations of impact and attrition breakage mechanisms with mill speed.

On the basis of 17 AG/SAG mill data sets the new

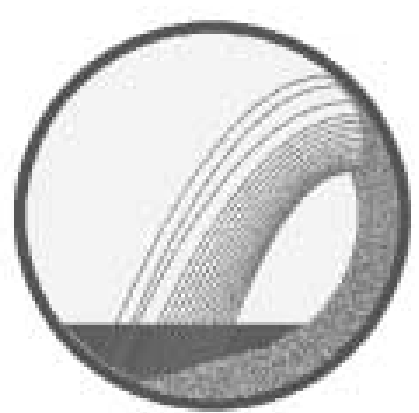

Fig. 11 Simulated Charge Profile Corresponding to a Lifter Bar of $120 \mathrm{~mm}$ and Angle of $90^{\circ}$ for a $9.6 \mathrm{~m}$ diameter SAG mill.

model was found to provide consistent estimations of both mill power draw and product size distribution. In both cases the differences between the standard deviation of the relative error associated with the estimations were very close to the data measurement standard error.

Even though the differences obtained for the mill power draw and product size distribution were relatively small, it should be emphasised that the high magnitude of the data relative error which may not be tolerable in greenfield estimations.

\section{Conclusions}

A model was developed to describe the influence of the charge composition and motion on breakage performance such that it can predict the performance of AG/ SAG mills under all normally encountered operational conditions. The parameters derived from the mechanistic description of the charge dynamics were incorporated into distributions of both impact and attrition breakage frequency and intensity. The validation exercise indicated that the new model predictions were better than an existing model as well as incorporates a number of additional features related to the mill design and operating conditions.

\section{Notation}

A grate open area

$a_{i j} \quad$ appearance function (fraction of broken particles from size fraction $\mathrm{j}$ which appears in size fraction i)

$\mathrm{a}_{\mathrm{ij}}{ }^{\text {att }}$ attrition appearance function

$a_{i j}{ }_{i j p}$ impact appearance function

C characteristic media size

$\mathrm{C}_{\mathrm{i}} \quad$ classification function at size $\mathrm{i}$ 
mill diameter

discharge rate of size fraction $i$

$\left(m^{2}\right)$

mass flowrate of size fraction $i$ in the

mill feed

$\mathrm{K}_{i}{ }^{\text {imp }}$ constant

$\mathrm{n}$ number of shells

$\mathrm{m}$ size fraction which contains media size lower

limit value

$\mathrm{N}_{s}{ }^{i m p}$ number of impact contacts per unit time given

$P_{i}^{i m p}$ impact partition term

$p_{i} \quad$ mass flow rate of size fraction $i$ in the mill discharge

Q flow rate through the grate

$r_{i} \quad$ breakage rate of size fraction $i$

$r_{i}^{i m p}$ impact breakage rate of size fraction i $\quad\left(h^{-1}\right)$

$r_{i}{ }^{\text {att }} \quad$ attrition breakage rate of size fraction $i \quad\left(h^{-1}\right)$

$s_{i} \quad$ mass of size fraction $i$ in the mill load

$\mathrm{s}_{\mathrm{i}}^{\mathrm{b}} \quad$ volume of all steel balls contained in size fraction $i$

$V_{m} \quad$ volume of the mill charge

$\varepsilon \quad$ total number of grinding charge particles

$\phi \quad$ fraction of mill critical speed

$\gamma \quad$ mean relative position of the grate apertures

$\Gamma^{\mathrm{imp}}$ specific impact generation rate by shell $\mathrm{s}\left(\mathrm{h}^{-1}\right)$

\section{Glossary}

angle of the lifter - angle formed between the lifter face and its base

appearance function - size distribution of broken fragments

breakage rates - frequency of breakage

comminution - process of size reduction

discharge function - description of the probability of a size fraction to be discharged from the mill chamber

grate - perforated steel plate installed in the mill discharge end designed to classify the mill charge

greenfield estimation - estimation not based on operating mill or pilot plant campaign

grinding media or contactors - coarse rocks and steel balls contained in the mill charge

JKM RC - Julius Kruttschnitt M ineral Research Centre, University of Queensland, Australia

JKSimM et - commercial software for mass balancing, modelling and simulation of comminution

lifter bar - steel bar installed in the mill internal wall to assist the charge lifting

matrix models - mathematical models where all variables are structured in matrices

mechanistic approach - representing a phenomenon by its mechanisms
$\mathrm{P}_{80}$ - size at which $80 \%$ of the mass passes of a given size distribution

rate process approach - mathematical description of comminution based on rates of change

reduction ratio - ratio between the characteristic sizes of the mill feed and discharge solids

shoulder of the charge - uppermost point reached by grinding media

slurry hold-up - pulp retention in the mill chamber

slurry pool - accumulation of pulp above the charge in the mill chamber

specific energy - energy per mass ( $\mathrm{kWh} /$ tonne) imparted to a fragment

toe of the charge - outermost point where the grinding media impact after a falling trajectory

trunnion - steel cylindrical projection forming the mill feed and discharge ends

tumbling test - test in which $3 \mathrm{~kg}$ of $-55+38 \mathrm{~mm}$ fragments are tumbled in a laboratory mill for 10 minutes

\section{References}

1) AUSTIN L.G., WEYMONT, N.P., PRISBREY, K.A., HOOVER, M., Preliminary results on modelling of autogenous grinding. Proc. $14^{\text {th }}$ Int. Symp. APCOM, 1977, p.207-26.

2) BOND, F.C., The third theory of comminution. Trans. AIM ME, 1952, 193, p.484-94.

3) GOLDMAN, M. and BARBERY, G., Wear and chipping of coarse particles in autogenous grinding: Experimental investigation and modelling. M inerals Engineering, 1988, 1 (1), p.67-76.

4) JOHNSON, G., HUNTER, I., HOLLE, H., Quantifying and improving the power efficiency of sag milling circuits. M inerals Engineering, 1994, 7 (2/ 3), p.141-152.

5) KELLY, F.J ., An empirical study of comminution in open circuit ball mill. Trans. CIM , 1970, 73, p.119-127.

6) KELLY, E.G. and SPOTTISWOOD, D.J., The breakage function; what is it really?. M inerals Engineering, 1990, 3 (5), p.405-414.

7) KING, R.P. and BOURGEOIS, F., M easurement of fracture energy during single-particle fracture. Minerals Engineering, 1993, 6 (4), p.353-367.

8) KJOS, D.M., 1985. Wet autogenous mills. In: SME M ineral Processing Handbook. WEISS, N.L., ed., SMEAIM E, 1985, Sec. 3C, chap.4, p.3C-60/ 3C-70.

9) LEUNG, K., An energy based ore specific model for autogenous and semi-autogenous grinding. Ph.D. Thesis, University of Queensland, Australia, 1987.

10) LOVEDAY, B.K. and NAIDOO, D., Rock abrasion in autogenous milling. M inerals Engineering. 1997, 10 (6), p.603-612.

11) M ANLAPIG, E.M., SEITZ, R.A., SPOTTISWOOD, D.J ., Analysis of the breakage mechanisms in autogenous 
grinding: In: Autogenous Grinding Seminar, 1979, de Trohdheim. p.A3/ 1-14.

12N M ACPHERSON, A.R., Autogenous grinding 1987 update. CIM Bulletin, 1987, 82 (921), p.75-82.

13) MORRELL, S., Simulation of bauxite grinding in semiautogenous mill and DSM screen circuit. M. Eng. Sc. Thesis, University of Queensland, Australia, 1989.

14) MORRELL, S., The prediction of power draw in wet tumbling mills. Ph.D. Thesis, University of Queensland, Australia, 1993.

15) MORRELL S., FINCH, W.M., KOJOVIC, T., DELBONI JR., H., Modelling and simulation of large diameter autogenous and semi-autogenous mills. Proc. Eur. Symp. Comm., Vol. 8, Stockholm, 1994.

16) MORRELL, S. and MORRISON, R.D., Ag and Sag mill circuit selection and design by simulation. Proc. Advances in Autogenous and Semiautogenous Grinding Technology. Sag 96, Vancouver, 1996.

17) MORRELL S. and STEPHENSON I., Slurry discharge capacity of autogenous and semi-autogenous mills and the effect of grate design. Int. J. M in. Proc. 1996, 112, p.53-72.

18) MÖRSKY, P., KLEMETTI, M., KNUUTINEN, T., KALAPUDAS, R., KOIVISTOINEN, P., The development of laboratory testing for autogenous grinding. Proc. Eur. Symp. Comm. Vol. 8, Stockholm, 1994, p.308317.
19) MUTAMBO, J.P.C., Further development of an autogenous and semi-autogenous mill model. M. Eng. Sc. Thesis, University of Queensland, Australia, 1992.

20) NAPIER-M UNN, T.J ., M ORRELL, S., MORRISON, R.D., KOJOVIC, T., Rock testing - determining the materialspecific breakage function. In: Mineral comminution circuits - their operation and optimisation. NapierM unn, T.J., ed., Chap.4, JKM RC, Brisbane, 1996, p.4994.

21) NARAYANAN , S.S., D evelopment of a laboratory single particle breakage technique and its application to ball mill modelling and scale up. Ph.D. Thesis, University of Queensland, Australia, 1985.

22) POWELL, M.S., The effect of liner design on the motion of the outer grinding elements in a rotary mill. Int. J. M in. Proc., 1991, 31, p.163-93.

23) SCHOENERT, K., 1993. Personal communications.

24) STANLEY, G.G., The autogenous mill: a mathematical model derived from pilot and industrial-scale experiment. Ph.D. Thesis, University of Queensland, Australia, 1974.

25) VERM EULEN, L.A. 1985. The lifting action of lifter bars in rotary mills. J ournal SAIM M , 85 (2), 1985, p.41-49.

26) WHITEN, W.J., A matrix theory of comminution machines. Chemical Eng. Sc., 1974, 29, p.589-599.

27) WICKHAM , P. 1972. Comminution of pebbles and fine ore. M. Eng. Sc. Thesis, University of Q ueensland, Australia, 1974.

\section{Author's short biography}
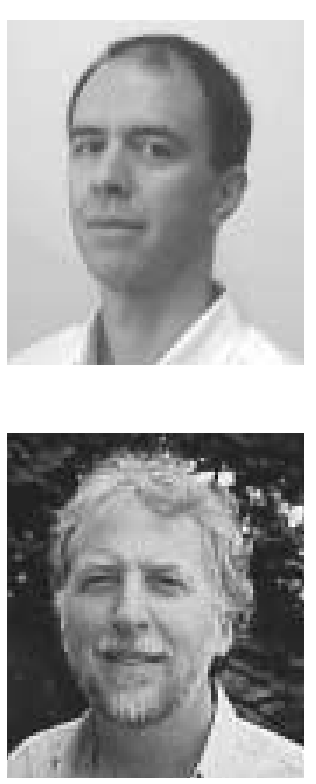

\section{Homero Delboni, J r.}

Dr. Homero Delboni, Jr. graduated in M ining Engineering from the University of São Paulo, B razil. In 1989 he obtained a M . Eng. degree in M inerals Engineering at the same university. He joined the Julius Kruttschnitt M ineral Research Centre in the University of Queensland, Australia, where he obtained his Ph.D. degree in 1999. He is currently a lecturer in the Department on M ining and Petroleum Engineering at the University of São Paulo, where he is involved in both teaching and research in mineral processing, particularly in comminution.

\section{Steve Morrell}

Dr. Steve Morrell graduated with Honours in M etallurgical Engineering from the Royal School of M ines. He joined the Julius Kruttschnitt M ineral Research Centre - JKM RC in the University of Q ueensland, Australia, where he obtained his M .Sc. degree in 1989 and Ph.D. in 1993. He is currently a researcher in the JKMRC, where he is involved in research in comminution. 